TERATOLOGY 66:65-72 (2002)

\title{
Turner Syndrome Morphology and Morphometrics: Cardiac Hypoplasia as a Cause of Midgestation Death
}

\author{
MASON BARR, JR. ${ }^{1-3 *}$ AND LORAINE OMAN-GANES ${ }^{1}$ \\ ${ }^{1}$ Teratology Unit, Department of Pediatrics, University of Michigan, Ann Arbor, Michigan 48109 \\ ${ }^{2}$ Teratology Unit, Department of Pathology, University of Michigan, Ann Arbor, Michigan 48109 \\ ${ }^{3}$ Teratology Unit, Department of Obstetrics, University of Michigan, Ann Arbor, Michigan 48109
}

\begin{abstract}
Background: A female fetus with massive truncal-limb hydrops and large, loculated, nuchal hygromas in midgestation is highly likely to have Turner syndrome. This phenotype is recognized to be usually lethal, with only more mildly affected fetuses surviving to term birth.

Methods: The morphology and morphometrics of 117 midgestation fetuses with phenotypic Turner syndrome were analyzed.

Results: More than $90 \%$ of fetuses with phenotypic Turner syndrome were found to have heart weights below the 2.5 centile, as well as lung hypoplasia and restricted limb growth for brain weight standards, although brain weight was only mildly reduced for gestational age. In contrast, subnormal heart weight was much less common among fetuses with other etiologies of hydrops, hygromas, or pleural effusions.
\end{abstract}

Conclusions: We hypothesize that myocardial hypoplasia is a primary defect in Turner syndrome, and it leads to or is a major contributor to the phenotypic features that end in midgestational death.

Teratology 66:65-72, 2002. ๑ 2002 Wiley-Liss, Inc.

\section{INTRODUCTION}

Turner syndrome is among the most common cytogenetic errors when assessed shortly after conception, constituting 1-2\% of all conceptions (Byrne et al., ' 85 ). Ninety-five to ninety-nine percent of affected fetuses are miscarried for reasons that are not entirely clear (Byrne et al., '85; Simpson et al., '93). The majority of Turner syndrome miscarriages occur during the embryonic period (Boue et al., '76; Byrne et al., '85). They are characterized as sacs or fragments of fetal membranes to which is attached a short cord with fragments of autolyzed embryo at the free end (Byrne et al., '85). Despite the high early mortality, a significant number survive to be recognizable in midgestation by in utero ultrasonography. The midgestation phenotype includes marked hydrops of the trunk and limbs, large and loculated hygromas of the posterolateral neck, pleural effusions, and ascites (Singh and Carr, '66). Other more subtle abnormalities may also be apparent.
An estimated 1:2,500 ${ }^{1}$ liveborn girls, will survive to be recognized as having Turner syndrome by their phenotypic appearance after delivery (Gorlin et al., '90).

It has been suggested that the cause of death in midgestation is related to a lymphatic anomaly (van der Putte, '77) and perhaps ultimately to heart failure (Byrne et al., '84). We would like to suggest that a lymphatic anomaly may not be the primary factor in the midgestation death of these fetuses, but rather that significant myocardial hypoplasia plays a central role.

We report on the morphology of midgestation fetuses with Turner syndrome, somatic and visceral morphometrics of midgestation fetuses with Turner syndrome, and the occurrence and associations of subnormal heart weight in Turner syndrome and other midgestation fetuses.

\section{MATERIALS AND METHODS}

From a collection of 117 Turner syndrome fetuses autopsied by the University of Michigan Teratology Unit, 112 fetuses were recognized to have massive hydrops and large, loculated nuchal hygromas. Seventytwo were detected by prenatal ultrasonography and 40 by examination after delivery. Five fetuses without ultrasonographic abnormalities were detected by amniocyte karyotyping done for advanced maternal age. Thirty-nine deliveries were by medical induction, 78 were spontaneous or augmented for prior fetal death. Fifty-nine fetuses with minimal to no maceration had at least brain and heart weights recorded. Among these, 34 also had complete information on other visceral weights and somatic measurements.

For comparative purposes, various data were drawn from the Teratology Unit database on fetuses weighing

Dr. Oman-Ganes' current address is 1110 Sheppard Avenue East, Suite 503, Toronto, Ontario M2K 2W2, Canada.

*Correspondence to: Mason Barr, Jr., MD, Teratology Unit, Pediatric Genetics, TC 1924, Box 0318, University Hospitals, Ann Arbor, MI 48109. E-mail: barr@med.umich.edu

Received 11 January 2002; Accepted 7 March 2002

Published online in Wiley InterScience (www.interscience.wiley.com). DOI 10.1002/tera.10064

${ }^{1}$ Other cited figures range from 1:2,000 to $1: 10,000$. 
TABLE 1. Morphologic findings in phenotypic Turner syndrome fetuses*

\begin{tabular}{lccc}
\hline Abnormality & $\begin{array}{c}\text { All TS fetuses } \\
(\mathrm{N}=117)\end{array}$ & $\begin{array}{c}\text { Confirmed 45, } \\
(\mathrm{N}=37)\end{array}$ & $\begin{array}{c}\text { Phenotype only } \\
(\mathrm{N}=80)\end{array}$ \\
\hline Hydrops (massive) & $112(96)$ & $32(86)$ & $80(100)$ \\
Nuchal hygromas (large) & $112(96)$ & $32(86)$ & $80(100)$ \\
Aortic coarctation & $93(79)$ & $28(76)$ & $65(81)$ \\
Bicuspid aortic valve & $43(41)$ & $17(46)$ & $26(38)$ \\
Bicuspid pulmonic valve & $11(10)$ & $6(16)$ & $5(7)$ \\
Left superior vena cava & $43(37)$ & $5(16)$ & $27(34)$ \\
Single umbilical artery & $21(18)$ & $3(8)$ & $16(20)$ \\
Aberrant subclavian artery & $7(6)$ & $4(11)$ & $4(5)$ \\
Other cardiac anomalya,b & $18(17)$ & $8(22)$ & $14(13)$ \\
Horseshoe kidney & $25(21)$ & $3(8)$ & $17(21)$ \\
Other kidney anomaly & $9(8)$ & $6(8)$ & \\
\hline
\end{tabular}

*Values are $n(\%)$.

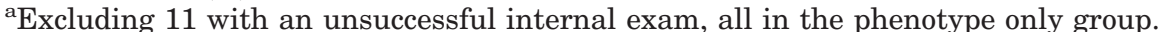

${ }^{b}$ Hypoplastic left heart (4) [aortic atresia (3)], atrioventricular septal defect (3), Ebstein anomaly (1), Tetralogy of Fallot (1), isolated atrial septal defect (4), isolated ventricular septal defect (5).

${ }^{\mathrm{c} H y d r o n e p h r o s i s ~(11), ~ e c t o p i a ~(4), ~ r o t a t i o n ~(10), ~ d u p l i c a t i o n ~(2) . ~}$

$50-1,000 \mathrm{~g}$ (brain $7-140 \mathrm{~g}$ ), that were stillborn with minimal to no maceration or, if liveborn, that died before $12 \mathrm{hr}$ of age. This provided a sample size of 1,741 , of which 887 were classified as normal on the bases of morphology and growth and 854 as abnormal due to morphologic or growth aberration. Special samples studied included those with generalized hydrops, nuchal hygromas, pleural effusions, or subnormal heart weight.

Normal growth standards for both body and brain weight had been developed from data on more than 1,000 normal mid to late gestation fetuses and are fully described in Barr et al. ('94). Because standards based on body weight are obviously unreliable in the presence of hydrops, brain weight standards were used to assess visceral growth. Observed measurements were converted to standard scores (the measurement observed less the expected value, divided by the expected SD). This allowed compilation and comparison of data from fetuses at various gestational ages and sizes. The $95 \%$ prediction interval was used to classify those at or below the 2.5 centile $(\mathrm{Z} \leftarrow 1.95)$ as subnormal.

For portions of the study, the estimated gestational age (13-24.3 weeks) was used. To determine age, the stated date of the last menstrual period was used, but corrections were made as indicated by early ultrasonography. In most cases the correction amounted to multiples of 28 days. The norms for somatic measurements and visceral weights by gestational age were derived from unpublished Teratology Unit data. Because only mean equivalent ages have been calculated, standard scores could not be generated for these analyses.

Sections for microscopy were prepared from seven subnormal weight Turner hearts and compared to those from both heart size- and age-matched normal fetuses. These H\&E-stained sections were examined independently and blindly by both authors to determine if there were any distinguishing features that allowed classification as to origin of the specimen.

\section{RESULTS}

\section{Turner morphology}

The combination of massive hydrops, affecting trunk and limbs, and large loculated nuchal hygromas is highly suggestive of monosomy X (Byrne, '84). A number of conditions other than Turner syndrome may produce hydrops/hygromas (Kalousek and Seller, '87); insofar as possible these diagnoses have been excluded from what is referred to here as phenotypic Turner syndrome. Of the 117 Turner syndrome fetuses, 37 had karyotypic confirmation. Five of these showed mosaicism (three were $45, \mathrm{X} / 46, \mathrm{XX}$, one was $45, \mathrm{X} / 46, \mathrm{Xr}(\mathrm{X})$, and one was $47, \mathrm{XX},+21 / 46, \mathrm{X}+21$ : two of these had hydrops and hygromas (one $\mathrm{X} / \mathrm{XX}$, one $\mathrm{X} / \mathrm{Xr}(\mathrm{X})$ ). Eighty fetuses did not have cytogenetic confirmation but nonetheless had strong morphologic evidence of Turner syndrome: characteristic combinations of trunk and limb hydrops, loculated nuchal hygromas, cavitary effusions, aortic coarctation, bicuspid aortic valve, horseshoe kidney, or persistent left superior vena cava, with no suggestion of another recognized syndrome. Those with and without cytogenetic confirmation of Turner syndrome were very similar in the frequency of the constituent abnormalities (Table 1). Other anomalies found were omphalocele (1), cord hernia (2), diaphragmatic hernia (1), Meckel diverticulum (2), postaxial adactyly (2), cleft palate (1), hypocalvaria (2), and "undescended" ovaries (6).

In contrast to the data in Table 1, the prevalences of malformations in term liveborn infants with Turner syndrome are: aortic coarctation $10 \%$, bicuspid aortic valve $30 \%$, renal anomalies $60 \%$ (Jones, '97). Another source gives: webbed neck (46\%), short broad neck (74\%), aortic coarctation or ventricular septal defect (10-16\%), renal anomalies (38\%: horseshoe kidney, unilateral renal agenesis, ureteral duplication) (Simpson et al., '93). Renal malformations were found in 33\% of 141 patients studied by Lippe et al. ('88). Bicuspid aortic valve was detected in $34 \%$ of 35 patients studied 
TABLE 2. Visceral and limb $z$-scores of Turner syndrome fetuses with and without hydrops and nuchal hygromas

\begin{tabular}{|c|c|c|}
\hline \multirow[b]{2}{*}{ Feature } & \multicolumn{2}{|c|}{$Z$-scores for brain weight (mean $\pm \mathrm{SD})$} \\
\hline & $\begin{array}{l}\text { With hydrops/hygromas } \\
(n=29)\end{array}$ & $\begin{array}{l}\text { No hydrops/hygromas } \\
(n=5)\end{array}$ \\
\hline Spleen & $0.17 \pm 1.73$ & $0.79 \pm 1.72$ \\
\hline Thymus & $-1.24 \pm 0.61$ & $0.28 \pm 0.92$ \\
\hline Thyroid & $-0.81 \pm 0.93$ & $0.69 \pm 1.20$ \\
\hline Heart & $-2.73 \pm 0.83$ & $-0.01 \pm 1.12$ \\
\hline Liver & $0.35 \pm 1.23$ & $0.18 \pm 1.51$ \\
\hline Adrenals & $-1.83 \pm 0.71$ & $-0.60 \pm 0.61$ \\
\hline Kidneys & $-0.80 \pm 1.29$ & $-0.53 \pm 0.61$ \\
\hline Lungs & $-2.75 \pm 0.97$ & $0.55 \pm 0.46$ \\
\hline Pancreas & $-0.72 \pm 0.75$ & $0.52 \pm 0.44$ \\
\hline Arm length & $-2.96 \pm 1.03$ & $-0.52 \pm 1.11$ \\
\hline Leg length & $-2.89 \pm 1.24$ & $-0.08 \pm 0.80$ \\
\hline Foot length & $-1.42 \pm 1.15$ & $0.45 \pm 2.11$ \\
\hline
\end{tabular}

by Miller et al. ('83). Sybert ('98) found 39\% of 244 Turner patients with echocardiograms had structural cardiovascular malformations, of which more than $50 \%$ were aortic coarctation or bicuspid aortic valve alone or in combination.

Mosaicism for monosomy $\mathrm{X}$ is associated with fewer malformations and lower likelihood of the hydropic/ hygromatous phenotype, and a greater chance of survival to term delivery (Ferguson-Smith, '65; Hall et al., '82). Simpson ('75), comparing 45,X with 45,X/46,XX karyotypes, noted reduction of neck webbing (46-26\%), aortic coarctation/ventricular septal defect (10-16 to 5-7\%), renal malformation (38-16\%), and lymphedema (38-26\%). Fetuses with mosaicism, however, may have the full-blown and lethal Turner phenotype, whereas fetuses with milder degrees of hydrops and smaller hygromas have been observed to improve and go on to term delivery.

Fewer liveborn Turner infants have cardiovascular or renal malformations than do midgestation fetuses, supporting that which has been repeatedly noted in the literature: hydropic/hygromatous fetuses are more severely affected with a much higher mortality than those who make it to term gestation. None of these associated malformations, however, is in and of itself noted for high prenatal lethality.

\section{Turner morphometrics}

Mean standard scores for the visceral and limb measurements are shown in Table 2, and graphically in Figure 1. Arm and leg lengths and heart, lung and adrenal weights were markedly diminished, whereas spleen and liver weights were effectively normal.

FitzSimmons et al. ('94) noted that fetuses with Turner syndrome already showed growth restriction in the second trimester. Our data support that observation. A plot of gestational age vs. mean equivalent age for observed measurement in 29 cases with hydrops and hygromas shows that crown-rump length and head circumference were not much different from controls, but there was a suggestion of some decline with advancing age (Fig. 2). Arm and leg lengths were notably
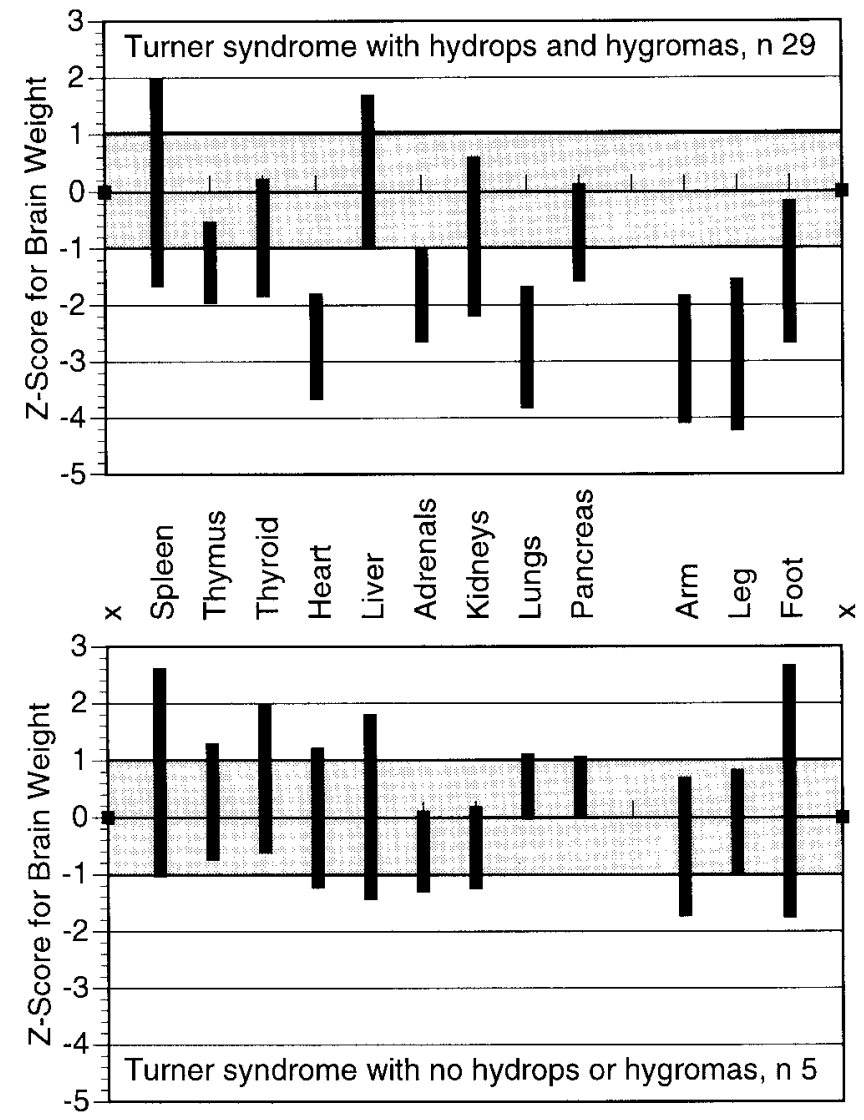

Fig. 1. Z-scores for visceral weights and limb measurements of Turner syndrome fetuses with and without the hydropic/hygromatous phenotype. Bars represent the mean $\pm 1 \mathrm{SD}$. The gray area is the mean $\pm 1 \mathrm{SD}$ of normal fetuses.

shortened early and were yet shorter at older ages. Foot length behaved similarly to limb lengths but in a less marked fashion. The weights of brain and spleen were not appreciably different from controls at any age. Thymus, thyroid, kidneys and pancreas were lighter than normal, and the difference appeared to increase with age. Adrenals, heart, and particularly lungs were 

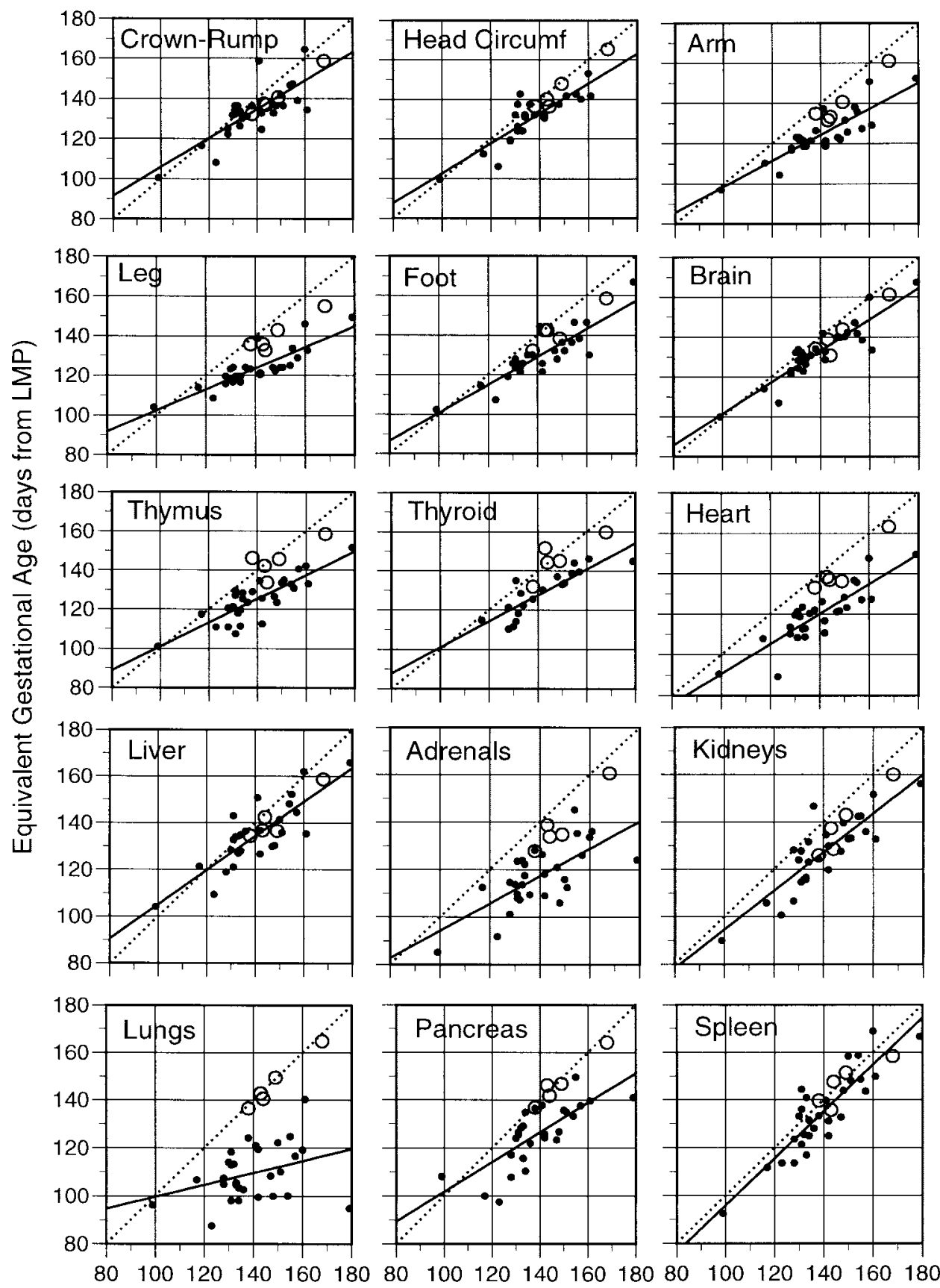

Gestational Age (days from LMP)
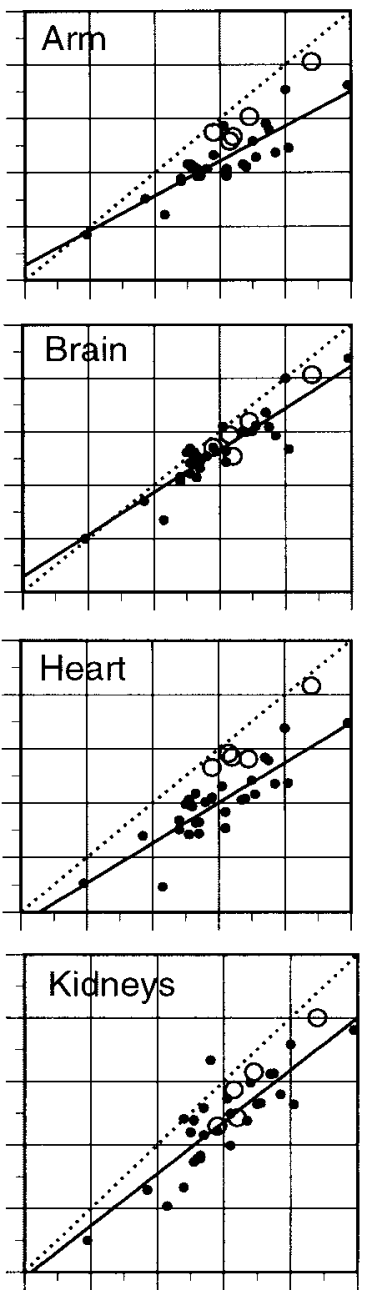

Fig. 2. Equivalent gestational age of various measurements plotted against estimated true gestational age for fetuses with Turner syndrome. Dots are fetuses with the hydropic/hygromatous phenotype, open circles are those without hydrops. The solid line is the observed linear regression for hydropic fetuses, the dashed line is the expected (normal) regression. very light compared to controls at all ages, and the difference was more marked in the older fetuses (Fig. 2).

The morphometrics of the five Turner fetuses with no hydrops or hygromas show no significant differences from controls (Figs. 1, 2, Table 2). Two of these fetuses had $\mathrm{X} / \mathrm{XX}$ mosaicism, one had trisomy 21 with $\mathrm{X} / \mathrm{XX}$ mosaicism, and two had a 45,X karyotype without significant anomalies.

That the lungs of fetuses with chronic and major pleural effusions should be small is not surprising. Pulmonary hypoplasia is well known to be associated with thoracic restriction or space-occupying internal lesions (tumors, effusions, herniated abdominal viscera) either by lung compression or impeded retention of pulmonary fluid (Moessinger et al., '90; Kitano et al., '98; Cilley et al., '00). The development of progressively shorter limbs appears to be a result of an imbalance between central and peripheral circulation. In the face of fetal hypotension or ischemia from a variety of causes, the limbs are noted to be shorter, presumably because peripheral circulation is curtailed to preserve central blood supply (Barr, '97). Why the adrenals are so small is less obvious, but may be a stress-related phenomenon. Stressors such as hypoxia and chorioam- 
nionitis have been associated with increased, not decreased, adrenal weight (Gaillard et al., '90; Barr, '98).

\section{Lymphatics}

van der Putte ('77) reported "the disorder [cystic hygroma in Turner syndrome] is essentially a generalized hypoplasia and partial agenesis of the lymphatic system, which ceases to extend peripherally at an early embryonic stage." This distal hypoplasia has been confirmed by Chitayat et al. ('89) and von Kaisenberg et al. ('99). van der Putte ('77) added "Furthermore, these three cases seem peculiar because no continuity was found to exist between the hygromata and the rest of the lymphatic system," representing a "serious underdevelopment of the jugulo-axillary lymph sacs." Such disconnection between the lymphatic vessels and venous system, although widely assumed, has not been confirmed.

Bendon ('01) suggested that the delayed lymphatic development might sequester protein, causing a low blood volume and hydrops due to hypoproteinemia. Shepard et al. ('86) found decreased serum albumin $(0.63 \pm 0.51 \mathrm{gm} / \mathrm{dl})$ in six midgestation Turner fetuses compared to controls $(1.90 \pm 0.66 \mathrm{gm} / \mathrm{dl})$. They speculated that hypoalbuminemia contributed to fetal edema by lowering intravascular oncotic pressure. In two of the fetuses total serum protein was not decreased, only albumin, and $\alpha$-fetoprotein was not measured. Greenberg et al. ('92) reported two infants with virtual absence of $\alpha$-fetoprotein but no hydrops. They equated this deficiency to analbuminemia, "a benign genetic defect" that similarly is not associated with hydrops (McKusick, '92). We suspect the hypoalbuminemia observed by Shepard et al. ('86) is more likely a secondary effect than a primary defect in Turner syndrome.

It is reasonable to ask which comes first, hydrops or central lymphatic outflow obstruction. An early onset of hydrops might impede not only distal lymphatic development but central venous connections as well. Excision of the thoracic duct in lamb fetuses caused hydrops and hypoproteinemia that was relatively mild and nonprogressive (Anders and Brace, '91). Furthermore, the blood volume of these lambs was not decreased. Central hydrops without appreciable limb involvement, as seen in many non- $45, \mathrm{X}$ cases, suggests peripheral lymphatics had developed and that hydrops in these fetuses may be due to increased venous pressure of later onset that impedes lymph outflow.

Tachycardia in the fetal lamb resulted in venous hypertension, decreased blood flow through the thoracic aorta, hypoproteinemia, and fetal hydrops (Nimrod et al., '87). When the tachycardia was relieved, the hydrops resolved. Elevated venous pressure in the lamb fetus impeded lymph outflow to the venous system (Brace, '89). If there were restriction of blood flow into and through the heart, venous pressure would be elevated. The caval dilation seen ultrasonographically in Turner fetuses suggests their venous pressure is indeed elevated.

\section{Heart}

Reporting on seven fetuses with cystic hygromas, Byrne et al. ('84) noted that four had hearts of subnormal weight. The basis for this judgment was not clear, however, only that the hearts were "markedly small according to fetal heart growth curves." 2 Byrne noted "Presumably, the severity of effect is related to the degree of hygroma development and concomitant hydrops, perhaps causing poor heart and lung growth. The exact mechanism of intrauterine death is unknown but may be related to excess fluid volume in the body coupled with heart failure" (Byrne et al., '84). A similar observation of "hypoplastic hearts," without further definition, was reported by Miyabara et al. ('97).

Our data show that 47 of 52 fetuses (90\%) with the Turner phenotype have remarkably small hearts (Fig. 3 ), averaging $3.33 \mathrm{SD}$ (0.04 centile) below the control mean for brain weight standards, whereas mean brain weight in these fetuses is only $1.37 \mathrm{SD}$ (8.5 centile) below the control mean for their gestational age. Subjectively small hearts were also noted in almost all of the macerated phenotypic Turner fetuses. Five fetuses with Turner syndrome had hydrops and hygromas but hearts that were within the $95 \%$ prediction interval. In one of these the degree of hydrops and size of the hygromas was subjectively less than usual (z-Heart -1.57), one had an atrioventricular septal defect (zHeart -0.37), one had a hypoplastic left heart with aortic atresia (z-Heart -1.30), and two had full blown hydrops/hygromas (z-Heart $-1.89,-1.93)$. Although these hearts were within the $95 \%$ prediction interval, all but one were well below the expected mean.

What does the small heart mean? We reason that if two hearts are of different weights, yet the size and spacing of the myocardial fibers and the thickness of the endo- and epicardium are the same, the smaller heart must have fewer cells. Light microscopy of these small hearts failed to reveal any features that distinguished them from either size- or age-matched controls, other than presumed myocardial hypoplasia. Of interest is the observation of Miyabara et al. ('97) that the aortas of Turner fetuses showed decreased smooth muscle cells and elastic fibers.

Considering the possibility that the myocardial hypoplasia is a result of the hydrops, fetuses with similar degrees of hydrops and hygromas, but not Turner syndrome, were examined. It was found that their hearts were mostly within (22) or above (7) the $95 \%$ prediction interval, with only six of 35 falling below the 2.5 centile (Fig. 4). This comparison of Turner fetuses to other hydropic/hygromatous fetuses indicates that the cardiac diminution is not an effect of generalized fluid accumulation.

Perhaps as Byrne et al. ('84) suggested, because the lymphatic malformation in Turner syndrome leads to

${ }^{2}$ The curves were possibly those of Potter and Craig ('75), which are based on body weight (see Byrne, '83). 

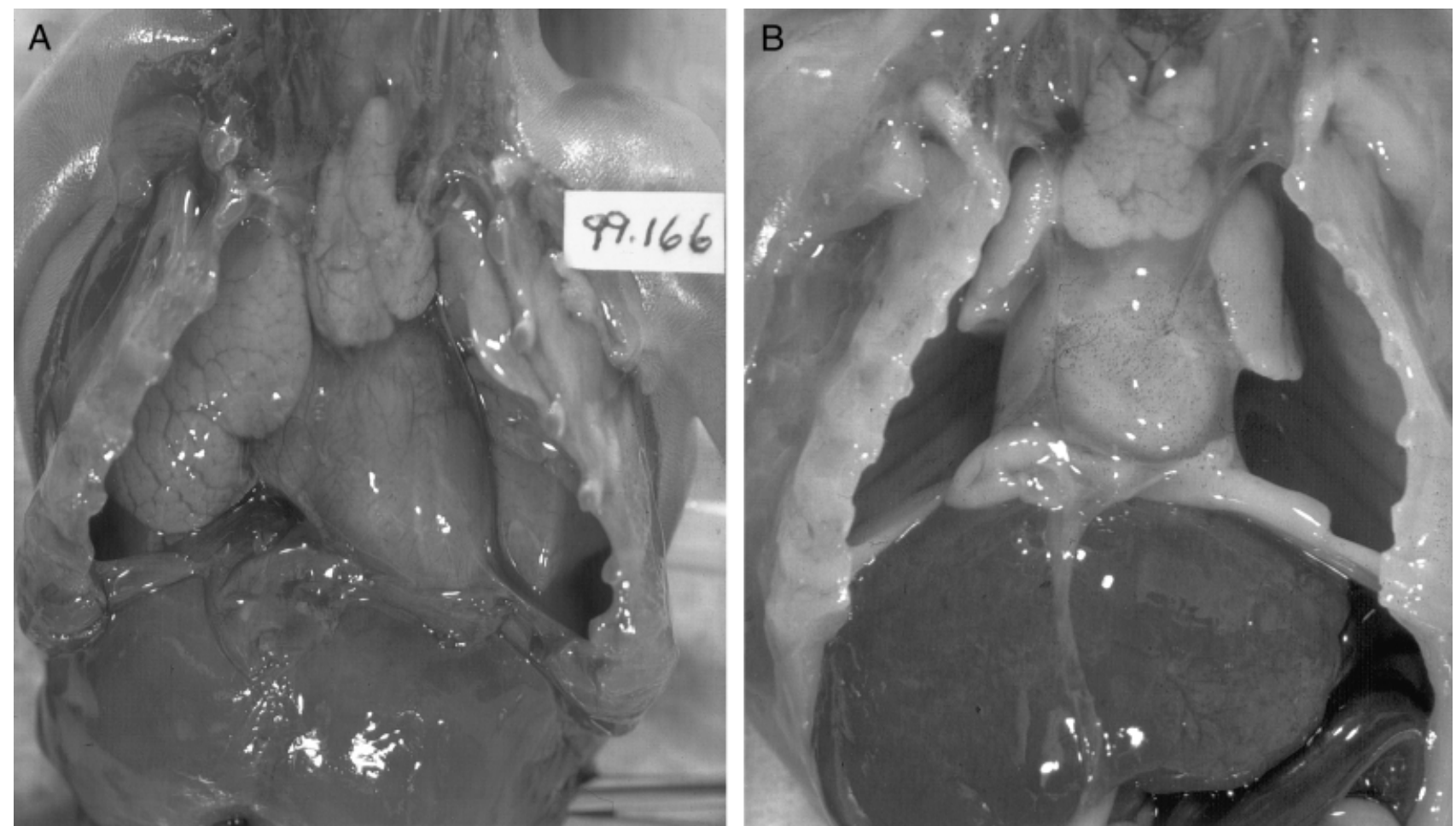

Fig. 3. Thoracic viscera in situ. A: Normal fetus of 21.7 weeks postmenstrual age; heart weight $0.61 \mathrm{SD}$ below mean. B: Turner syndrome fetus of 21.6 weeks postmenstrual age; heart weight 3.37 SD below mean, hypoplastic lungs, dilated right atrium.

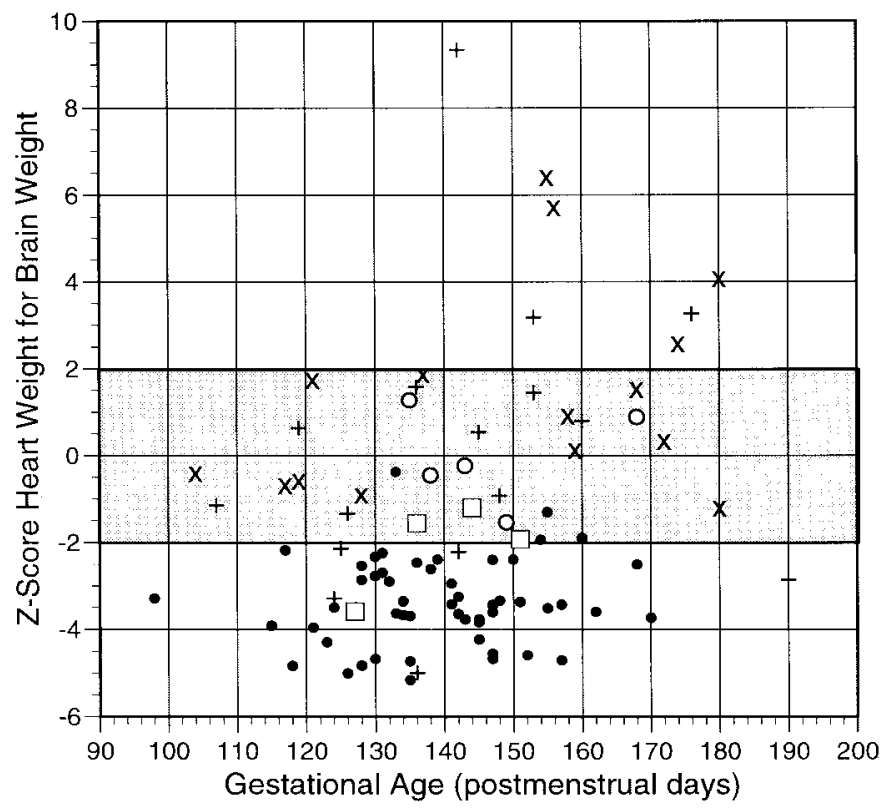

pleural effusion, cardiac growth would be compromised by a mechanism similar to that which is presumed to interfere with lung growth. If that were so, it would be anticipated that fetuses with pleural effusions of other etiologies would likewise have small hearts. Pleural effusions in and of themselves, however, do not seem to be responsible for the small hearts observed. Of 75
Mean Z-Scores:

\section{Turner Syndrome \\ With hydrops and hygromas \\ $-3.33 \pm 1.02, \mathrm{n} 54(\bullet)$}

No hydrops or hygromas

$-0.01 \pm 1.12, v 5$ (o)

\section{Not Turner Syndrome}

With hydrops and hygromas

$0.12 \pm 3.37, \mathrm{n} 16(+)$

With hydrops only

$1.42 \pm 2.38, \mathrm{n} 15(\mathrm{X})$

With hygromas only $-2.07 \pm 1.06, \mathrm{n} 4$ (口)

Fig. 4. Z-Scores of heart weight for brain weight standards by gestational age, for fetuses with and without Turner syndrome, and with and without hydrops or nuchal hygromas. The gray area represents the normal $95 \%$ prediction interval.

fetuses with pleural effusions $68 \%$ did not have a light heart, in fact $13 \%$ had a heavy $(Z>1.95)$ heart. Of the $32 \%$ with light hearts associated with pleural effusions, $67 \%$ had Turner syndrome. Of the eight nonTurner fetuses with pleural effusions and a small heart, there were two (males) with unclassified nonimmune hydrops, two with trisomy 13 , and one each with 
a dup $13 q$ chromosome anomaly, fetal akinesia sequence, hypoplastic right heart, and unclassifiable multiple malformations. It should be noted that Cadkin and Pergament ('93) reported pleural effusions in Turner syndrome were present at 8.5 weeks of gestation. Thus it remains a possibility that the very early onset and chronicity of pleural effusions are capable of restricting myocardial growth.

Clark ('84) reviewed case reports of 193 women with Turner syndrome and noted an association between neck webbing and coarctation of the aorta: coarctation in $25 \%$ of those with a webbed neck vs. $3 \%$ of those without a webbed neck. He suggested a pathogenetic relationship between the two, hypothesizing that "increased lymphatic pressure associated with jugular lymphatic sac obstruction distends the thoracic ducts, which compress the ascending aorta altering intracardiac blood flow." In support of this hypothesis, Berdahl et al. ('95) reported that neck webbing was associated with flow-related cardiac defects, irrespective of the basic diagnosis such as trisomy 21, Turner syndrome, or Noonan syndrome. It seems unlikely to us, however, that thoracic duct distention would compress the ascending aorta because the course of the thoracic duct is situated closer to the left subclavian artery than the ascending aorta. Nonetheless, we do note that seven fetuses without coarctation of the aorta had a mean z-Heart of -0.55 ( 2 had hydrops/hygromas), compared to a mean z-Heart of -2.79 in those with aortic coarctation. Both Miyabara et al. ('97) and Lacro et al. ('88) noted dilated lymphatics around the ascending aorta and main pulmonary artery in Turner fetuses. Although they noted an association between lymphatic aberration and left-sided defects, Lacro et al. ('98) found no correlation between the degree of aberration and the cardiac pathology. On examination of microscopic sections of seven Turner hearts, we did not find any evidence of dilated cardiac lymphatics. Our sections were parallel to the blood flow pattern, however, whereas the sections studied by Lacro et al. ('98) and Miyabara et al. ('97) were transverse across the outflow tracts, which could possibly explain the difference in observations.

To determine if other factors were associated with subnormal heart weight in midgestation fetuses, the Teratology Unit database was searched for all instances of Z-scores of heart for brain or body weight that were below the 2.5 centile (Table 3 ). After exclusion of the fetuses with Turner syndrome, the remainder were surveyed for other diagnoses. Fourteen of 34 fetuses with trisomy 13 had a small heart for body weight standards, and only four were small for brain weight standards, the remainder having a subnormal brain weight associated with holoprosencephaly. Four of 37 fetuses with trisomy 18 had small hearts for brain weight standards. Three donor twins in the twin-transfusion syndrome had small hearts for both body and brain standards. Five fetuses had hydrops of other etiologies and small hearts. Others had a wide variety of abnormalities (e.g., unclassifiable multi-organ mal-
TABLE 3. Prevalence of subnormal heart weights among fetuses classified as abnormal, excluding those with Turner syndrome

\begin{tabular}{lcc}
\hline & All & \\
& abnormal \\
& $\begin{array}{c}\text { Excluding Turner } \\
n(854)\end{array}$ & $\begin{array}{c}\text { Exclundrome }(829)^{\mathrm{a}} \\
\text { seture }\end{array}$ \\
\hline z-Heart for body $<-1.95$ & $90(10.5)$ & $86(10.4)$ \\
z-Heart for brain $<-1.95$ & $119(13.9)$ & $94(11.3)$ \\
Both z-Heart $<-1.95$ & $58(6.8)$ & $33(4.0)^{\mathrm{b}}$ \\
\hline
\end{tabular}

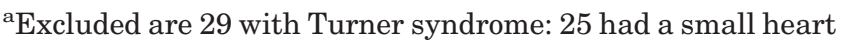
for both body and brain weight standards, four had a small heart for body weight standards only.

${ }^{\mathrm{b}}$ Five were hydropic.

formations, cystadenoma of the lung, thanatophoric dysplasia, short rib-polydactyly syndrome, achondrogenesis, etc.), with no more than two examples of any one diagnosis. In summary, the only diagnosis found with a high percentage of small hearts was Turner syndrome.

\section{CONCLUSION}

Rather than attributing the midgestation death of Turner syndrome fetuses to the hydrops per se, we suggest another possibility: that the heart is primordially growth restricted that leads to the other effects. We reason that the only thing that would result in a reduced heart weight is myocardial hypoplasia. Light microscopy of these small hearts failed to reveal any features that distinguished them from either size- or age-matched controls, other than presumably fewer myocardial cells.

An undersized heart could impede venous return and thereby elevate venous pressure. Venous hypertension would impede lymphatic outflow producing hydrops. Cardiac output would also be diminished. Circulatory balance would be adjusted to favor circulation to the brain at the expense of the extremities, resulting in sparing of brain growth but shortened limbs. Peripheral ischemia could eventually lead to capillary leakage, contributing to hypoproteinemia. The increased volume of extravascular fluid, particularly if it has an early onset, could interfere with distal lymphatic development and at the same time also interfere with central lymphatic return to the venous system. Accelerated pleural effusions could further impede heart and lung growth and venous return. This cycle could continue until the compromise is so severe that the fetus dies in utero in midgestation. The only Turner fetuses that would survive to be liveborn would be those with minimally restricted heart growth, also being those with mild or no hydrops.

Not every fetus with a small heart develops hydrops, nor does every fetus with hydrops have a small heart. The concordance of small heart and hydrops in Turner syndrome is so striking a phenomenon, however, that it indicates there is a pathogenetic relationship. Whether or not myocardial hypoplasia is a primary abnormality 
in Turner syndrome, we believe that it does play a central role in the midgestation death of many affected fetuses.

\section{LITERATURE CITED}

Anders RL, Brace RA. 1990. The development of hydrops fetalis in the ovine fetus after lymphatic ligation or lymphatic excision. Am J Obstet Gynecol 162:1331-1334.

Barr M. 1997. Growth as a manifestation of teratogenesis: lessons from human fetal pathology. Reprod Toxicol 11:583-587.

Barr M. 1998. Correlates of prenatal visceromegaly. Am J Med Genet 79:249-252.

Barr M, Blackburn WR, Cooley NR. 1994. Human fetal somatic and visceral morphometrics. Teratology 49:487-496.

Bendon RW. 2001. Review of some causes of stillbirth. Pediatr Dev Pathol 4:517-531.

Berdahl LD, Wenstron KD, Hanson JW. 1995. Web neck anomaly and its association with congenital heart disease. Am J Med Genet 56:304-307.

Boue J, Philippe E, Giroud A, Boue A. 1976. Phenotypic expression of lethal chromosomal anomalies in human abortuses. Teratology 14: 3-20.

Brace RA. 1989. Effects of outflow pressure on fetal lymph flow. Am J Obstet Gynecol 160:494-497.

Byrne J. 1983. Fetal pathology laboratory manual. Birth Defects Orig Artic Ser 19:48.

Byrne J, Blanc WA, Warburton D, Wigger J. 1984. The significance of cystic hygroma in fetuses. Hum Pathol 15:61-67.

Byrne J, Warburton D, Kline J, Blanc W, Stein Z. 1985. Morphology of early fetal deaths and their chromosomal characteristics. Teratology 32:297-315.

Cadkin A, Pergament E. 1993. Bilateral pleural effusion at 8.5 weeks' gestation with Down syndrome and Turner syndrome. Prenat Diagn 13:659-660.

Chitayat D, Kalousek DK, Bamforth JS. 1989. Lymphatic abnormalities in fetuses with posterior cervical cystic hygroma. Am J Med Genet 33:352-356.

Cilley RE, Zgleszewski SE, Chinoy MR. 2000. Fetal lung development: airway pressure enhances the expression of developmental genes. J Pediatr Surg 35:113-118.

Clark EB. 1984. Neck web and congenital heart defects: a pathogenic association in $45 \mathrm{X}-\mathrm{O}$ Turner syndrome? Teratology 29:355-361.

Ferguson-Smith M. 1965. Karyotype-phenotype correlations in gonadal dysgenesis and their bearing on the pathogenesis of malformations. J Med Genet 2:142-154.

FitzSimmons J, Fantel A, Shepard TH. 1994. Growth parameters in mid-trimester fetal Turner syndrome. Early Hum Dev 38:121-129.

Gaillard DA, Lallemond AV, Moirot HH, Visseaux-Coletto BJ, Paradis PH. 1990. Fetal adrenal development during the second trimester of gestation. Pediatr Pathol 10:335-350.

Greenberg F, Faucett A, Rose E, Bancalari L, Kardon NB, Mizejewski G, Haddow JE, Alpert E. 1992. Congenital deficiency of alphafetoprotein. Am J Obstet Gynecol 167:509-511.

Gorlin RJ, Cohen MM Jr, Levin LS. 1990. Syndromes of the head and neck. 3rd Ed. New York: Oxford University Press. p 54-58.
Hall JG, Sybert VP, Williamson RA, Fisher NL, Reed SD. 1982. Turner's syndrome. West J Med 137:32-44.

Jones KL. 1997. Smith's recognizable patterns of human malformation. Philadelphia: WB Saunders Co. p 81-83.

Kalousek DK, Seller MJ. 1987. Differential diagnosis of posterior cervical hygroma in previable fetuses. Am J Med Genet 3(Suppl): 83-92.

Kitano Y, Yang EY, von Allmen D, Quinn TM, Adzick NS, Flake AW. 1998. Tracheal occlusion in the fetal rat: a new experimental model for the study of accelerated lung growth. J Pediatr Surg 33:17411744.

Lacro RV, Jones KL, Benirschke K. 1988. Coarctation of the aorta in Turner syndrome: a pathologic study of fetuses with nuchal cystic hygromas, hydrops fetalis, and female genitalia. Pediatrics 81:445451 .

Lippe B, Geffner ME, Dietrich RB, Boechat MI, Kangarloo H. 1988. Renal malformations in patients with Turner syndrome: imaging in 141 patients. Pediatrics 82:852-856.

McKusick VA. 1992. Mendelian inheritance in man. 10th Ed. Baltimore: Johns Hopkins University Press. p 40.

Miller MJ, Geffner ME, Lippe BM, Itami RM, Kaplan SA, DiSessa TG, Isabel-Jones JB, Friedman WF. 1983. Echocardiography reveals a high incidence of bicuspid aortic valve in Turner syndrome. J Pediatr 102:47-50.

Miyabara S, Nakayama M, Suzumori K, Yonemitsu N, Sugihara H. 1997 Developmental analysis of cardiovascular system of 45,X fetuses with cystic hygroma. Am J Med Genet 69:135-141.

Moessinger AC, Harding R, Adamson TM, Singh M, Kiu GT. 1990. Role of lung fluid volume in growth and maturation of the fetal sheep lung. J Clin Invest 86:1270-1277.

Nimrod C, Davies D, Harder J, Iwanicki S, Kondo C, Takahashi Y, Maloney J, Persaud D, Nicholson S. 1987. Ultrasound evaluation of tachycardia-induced hydrops in the fetal lamb. Am J Obstet Gynecol 157:655-659.

Potter EL, Craig JM. 1975. Pathology of the fetus and the infant. 3rd Ed. Chicago: Year Book Medical Publishers. p 18.

Shepard TH, Wener MH, Myhre SA, Hickok DE. 1986. Lowered plasma albumin concentration in fetal Turner syndrome. J Pediatr 108:114-116.

Simpson JL. 1975. Gonadal dysgenesis and abnormalities of the human sex chromosomes: current status of phenotypic-karyotypic correlations. Birth Defects Orig Artic Ser 11:23-59.

Simpson JL, Verp MS, Plouffe L Jr. 1993. Female genital system: gonadal dysgenesis. In Stevenson RE, Hall JG, Goodman RM, editors. Human malformations and related anomalies. Vol. 2. New York: Oxford University Press. p 565-568.

Singh RP, Carr DH. 1966. The anatomy and histology of XO human embryos and fetuses. Anat Rec 155:369-383.

Sybert VP. 1998. Cardiovascular malformations and complications in Turner syndrome. Pediatrics 101:E11.

van der Putte SCJ. 1977. Lymphatic malformation in human fetuses: study of fetuses with Turner syndrome or status Bonnevie-Ullrich. Virchows Arch A Pathol Anat Histol 376:233-246.

von Kaisenberg CS, Nicolaides KH, Brand-Saberi B. 1999. Lymphatic vessel hypoplasia in fetuses with Turner syndrome. Hum Reprod 14:823-826. 